\title{
Centennial History of Yonsei University Dermatology in Korea: 1917 to 2017
}

\author{
Jihee Kim, Tae-Gyun Kim, Si Hyung Lee, Min Kyung Lee, Jong Hoon Kim, Sang Eun Lee, \\ Do Young Kim, Mi Ryung Roh, Chang Ook Park, Ju Hee Lee, Min-Geol Lee, Dongsik Bang ${ }^{1}$, \\ Sang Ho Oh, Kee Yang Chung
}

Department of Dermatology and Cutaneous Biology Research Institute, Yonsei University College of Medicine, Seoul, ${ }^{1}$ Department of Dermatology, Catholic Kwandong University International St. Mary's Hospital, Incheon, Korea

Yonsei Dermatology celebrated its centennial in 2017, marking 100 years since Kung Sun Oh established the first Department of Dermatology and Urology in Korea in 1917. Following the footsteps of Kung Sun Oh, a pioneer of Korean dermatology, its members united and worked to provide the best medical service and achieve academic milestones in dermatology. Over the past hundred years, Yonsei Dermatology has played a pivotal role in the advancement of medical science and academia in Korea. The main activities of the department include medical care, education, and dermatologic research. Its research activities have encompassed a wide spectrum of dermatologic manifestations from skin immunology and pathology to introduction of newly developed treatment technologies. As Kung Sun Oh was the first Korean professor of dermatology at Severance Medical School and a passionate educator, we continue to serve his will by nurturing medical students and dermatology special-

Received March 23, 2018, Accepted for publication March 23, 2018

Corresponding author: Sang Ho Oh, Department of Dermatology and Cutaneous Biology Research Institute, Yonsei University College of Medicine, 50-1 Yonsei-ro, Seodaemun-gu, Seoul 03722, Korea. Tel: 82-2-2228-2080, Fax: 82-2-393-6947, E-mail: oddung93@yuhs.ac ORCID: https://orcid.org/0000-0002-4477-1400

Kee Yang Chung, Department of Dermatology and Cutaneous Biology Research Institute, Yonsei University College of Medicine, 50-1 Yonsei-ro, Seodaemun-gu, Seoul 03722, Korea. Tel: 82-2-2228-2080, Fax: 82-2-393-6947, E-mail: kychung@yuhs.ac

ORCID: https://orcid.org/0000-0003-3257-0297

This is an Open Access article distributed under the terms of the Creative Commons Attribution Non-Commercial License (http://creativecommons. org/licenses/by-nc/4.0) which permits unrestricted non-commercial use, distribution, and reproduction in any medium, provided the original work is properly cited.

Copyright (c) The Korean Dermatological Association and The Korean Society for Investigative Dermatology ists to serve as global medical leaders. The Kung Sun Oh Memorial Lecture, first hosted in 1977, was the beginning of mutual international academic exchange in the field of dermatology in Korea. The memorial lecture has played a major role in advancing the academic status of Korean dermatological science by inviting distinguished dermatologists from around the world as guest lecturers. Yonsei Dermatology has played a key role in the history of modern medicine and dermatology in Korea over the last 100 years and continues to make an impact. (Ann Dermatol 30(5) $513 \sim 521,2018$ )

\section{-Keywords-}

Dermatology, Kung Sun Oh, Severance, Yonsei

\section{INTRODUCTION}

\section{The beginning of modern medicine and Yonsei University College of Medicine}

An American medical missionary, Horace N. Allen, planted the seed for modern medicine in Korea. Established in 1885 during the Gapsin Coup, Gwanghyewon was the nation's first modernized hospital (Fig. 1A). In the same year, it was renamed Chejungwon "House of Civilized Virtue". From the beginning, the medical services at the Chejungwon covered various sub-specialties of modern western medicine, including dermatology and venereology. From 1986, Horace N. Allen provided the first basic medical education in Korea. After Oliver R. Avison's nomination as the fourth director of the Chejungwon in 1893, the institution began to emphasize the importance of medical education for future generations. In 1904, the Chejungwon changed its name to Severance Hospital in commemoration of 

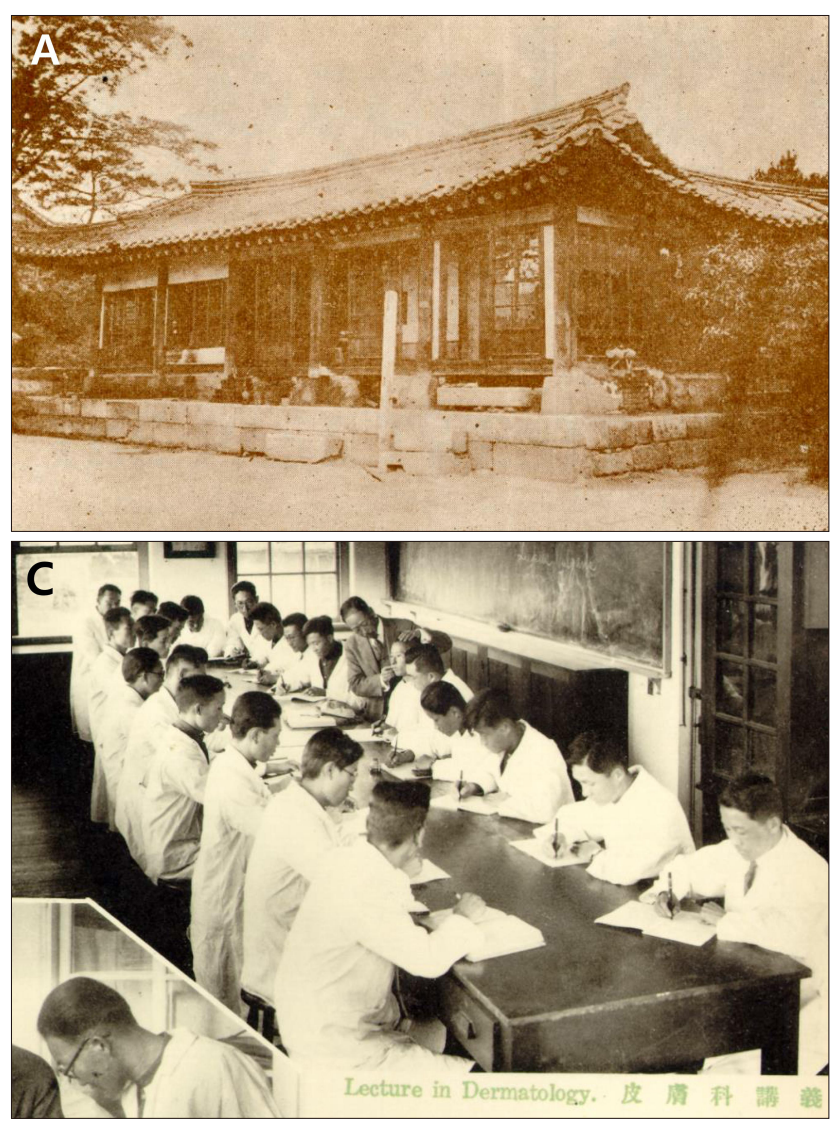

Louis Severance, who donated a large sum of money to build a new hospital building near Sungnyemun gate ${ }^{1}$. In the same year, the name of early medical school changed to Severance Hospital Medical School. The first seven medical licenses in Korean history were awarded to graduates of Severance Hospital Medical School in 1908, who all later became paramount figures in the establishment of modern medicine. The name of the medical school was aptly changed to Severance Union Medical School in 1913; later renamed as Severance Union Medical College in 1921, along with the appointment of lectures from various mission boards. Eventually, the early roots of Chejungwon provided solid foundation of Severance Hospital and Yonsei University College of Medicine in Yonsei University Health System (YUHS), as we know it today (Fig. 1B). Current facilities of YUHS encompass three colleges (Medicine, Dentistry, Nursing) and five hospitals (Severance Hospital, Gangnam Severance Hospital, Dental Hospital, Yongin Severance Hospital).

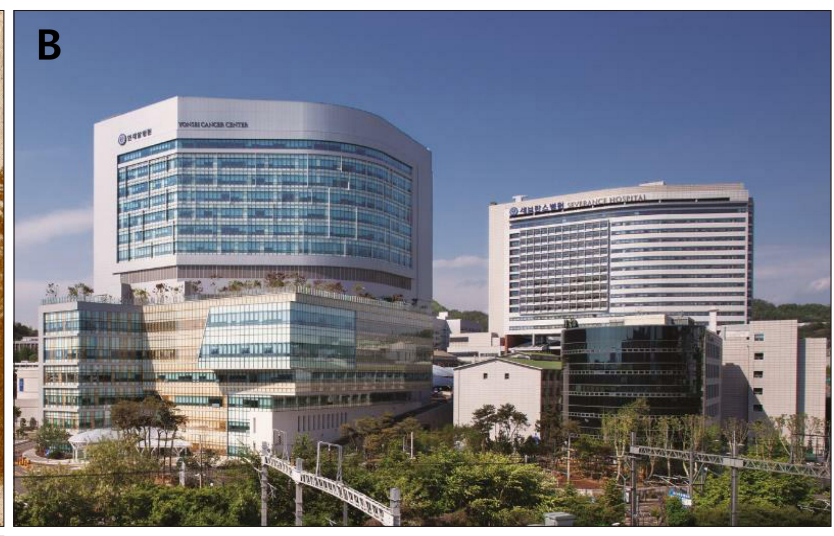

Fig. 1. (A) Kwanghyewon, renamed as Chejungwon (House of Civilized Virtue), at its opening as the Korea's first modernized hospital in 1885. (B) Present day Yonsei University Health System in 2017. (C) Lecture in Dermatology by Kung Sun Oh, the founder of Yonsei Dermatology, in 1931. The students were taught 'Lupus Vulgaris' as indicated in the blackboard. Adapted from Bang and Chung. Early Roots of Western Medicine and a Pioneer of Social Work in Korea: Dr. Kung Sun Oh (1878-1963). Yonsei Med J 2016;57:277-2826.

\section{YONSEI DERMATOLOGY: EARLY YEARS TO CURRENT DEPARTMENT}

Kung Sun Oh $(1913 \sim 1942$, dates indicate the years served at Yonsei University College of Medicine): founder of Yonsei Dermatology

Kung Sun Oh was the second Korean to receive medical education in the US. In 1907, he graduated from the University of Louisville, School of Medicine. During his medical school years in the US, Kung Sun Oh studied dermatology under John Edwin Hays. Kung Sun Oh returned to Korea after graduation and served medical missions in medically isolated areas in Korea. Kung Sun Oh first came to Severance Union Medical School in 1913, as he was commissioned by the mission board of the US Southern Presbyterian Church to be dispatched to Medical School as an assistant professor ${ }^{2}$. As the first Korean professor at Severance Union Medical School, he provided supplementary teaching in Korean to medical students on diverse subjects, including internal medicine, surgery, and basic science, as well as dermatology (Fig. 1C) ${ }^{3}$. In 1916, Kung Sun Oh visited Tokyo Imperial University for a year, to study dermatology and urology under Ikuzo Toyama. In May 1917, the Department of Dermatology and Urology 
was established at Severance Union Medical School and Kung Sun Oh was appointed as the first chair of the department. Since then, he served the department for 18 years. During his professorship, Kung Sun Oh visited University of Vienna in 1930 to seek latest knowledge in field of dermatology. Afterwards, he dedicated his life to education, especially to the development of Medical School $^{4,5}$.

Kung Sun Oh was revered for his contributions to social welfare service in Korea. In 1919, he established Korea's first orphanage named Gyeongseong Orphanage. Additionally, he established Gyeongseong Nursing Home for the elderly in 1931. After his retirement, he took care of more than 2,400 orphans as the director of the orphanage and devoted the rest of life to social work until his passing. He received the Order of Cultural Merits, Republic of Korea Medal and Sopa Award from the Korean Children's Association for enhancing child welfare in Korea ${ }^{6}$.

\section{YONSEI DERMATOLOGY: BRIEF HISTORY OF THE DEPARTMENT}

Following in the footsteps of Kung Sun Oh, Young Joon Lee became the second chair of the Department of Dermatology and Urology between 1934 and 1942 and served as the third Dean of Severance Union Medical College. He also served as a congressman, Secretary General of the Korean Red Cross and the Vice Speaker of the National Assembly. Hak Song Lee, served as the third chair between 1943 and 1946 of the department, and played a pivotal role in establishing the present day internship and residency training program at Severance Hospital. In 1943, he was appointed as the Superintendent of the Severance Hospital. In 1949 he became the chairman in the department of Urology at Seoul National University College of Medicine. Sang Yo Lee was the fourth chairperson of the Department of Dermatology and Urology at Severance Union Medical College between 1947 and 1949. Sang Yo Lee and Chong Soon Wang joined as the first board members of Korean Dermatological Association (KDA), which was separated as independent organization from Chosun Dermato-Urology Association in 1954. Chong Soon Wang $(1939 \sim 1981)$ was the fifth and seventh chairperson. He served as the first president of the department of Urology after the separation of the two departments in 1960. Nam Zoo Lee (1949 1966) served as the sixth chairperson and when the department separated in 1960 into two independent departments, he became the eighth chairperson of dermatology. The inauguration of the first chair of the independent department marked the beginning of the Yonsei Dermatology. During his term, Nam Zoo Lee was commissioned as the 20th president of the KDA. Hak Song Lee and Nam Zoo Lee served as early committee members of KDA who were appointed to establish qualification board exam systems. Tae Ha Woo (1959 1975) served as the ninth department chairperson and served as the 31st (1982 1984) president of the KDA. Tae Ha Woo donated the first office for its use as KDA headquarters in 1981 in Gangnam-gu, Seoul. Sungnack Lee $(1975 \sim 1990)$ served as the tenth chairperson, and during his service, he actively promoted international academic exchange, inspired passion for research, and contributed to the acquisition of new medical knowledge from abroad. He also played a major role in elevating the departmental status to an international level by securing and establishing a sub-specialty for each professor. Following this, in chronological order, Jung Bock Lee, Yoon-Kee Park, Dongsik Bang, Seung Hun Lee, Kwang Hoon Lee, and Min-Geol Lee served as chairpersons. Currently, Kee-Yang Chung is serving as the 17th chairperson of the department since 2015. All professors have contributed to the development of Korean dermatology by continuously engaging in academic research and focusing on training the next generation.

\section{CLINICAL AND BASIC RESEARCH ACTIVITIES OF YONSEI DERMATOLOGY}

From the very beginning, Yonsei Dermatology has played a pivotal role in the advancement of dermatological science and introduced key diagnostic and treatment pearls in Korea.

\section{Venereology: sexually transmitted diseases and syphilis}

Around 1924, Kung Sun Oh first documented the prevalence of sexually transmitted disease in Korea during his service as a professor of dermatology and urology at Severance Union Medical College. He campaigned against prostitution to prevent transmission of venereal infections. Following his footsteps, in 1972, the department introduced the first fluorescent treponemal antibody-absorption (FTA-ABS) test in Korea in cooperation with the Department of Clinical Pathology. Further full-scale research was initiated when Sungnack Lee served as the chair of the department. Jung Bock Lee initiated the basic laboratory work in the field of syphilis in 1982, and Min-Geol Lee and Hyung-II Kim joined the team to establish the 19S(IgM)-FTA test for syphilis diagnosis. The test has been clinically applied to diagnose active syphilis since $1984^{7}$. In the meantime, Jung Bock Lee received a Fogarty International Research Fellowship from the National Cancer Institute (NIH) in the US, and 
studied the diagnostic role of enzyme-linked immunosorbent assay (ELISA) for specific immunoglobulin $M$ in neurosyphilis ${ }^{8}$. During the 1980s and 1990s, Jung Bock Lee and Min-Geol Lee heavily focused on molecular and biochemical tools to enhance the accuracy of diagnosis of syphilis. Based on our advanced laboratory techniques for syphilis serology, we hosted six annual course works titled 'International Laboratory Course on Serologic Tests for Syphilis' from 1986 to 1992 to educate doctors from Southeast Asia and Africa.

\section{Behçet's disease}

Until the 1980s, Behçet's disease was an unfamiliar disease entity in Korea. Sungnack Lee had experienced the importance of Behçet's disease while studying with Theodor Nasemann. Together with Dongsik Bang, he helped introduce Behçet's disease to Korea. In 1983, the very first Behçet's disease specialty clinic in Korea was opened at Severance Hospital. The clinic significantly contributed to heighten public perception of the disease in Korea, and nowadays, more than 10,000 patients are registered in its cohort ${ }^{9}$.

In 1985, the first presentation on Behçet's disease in Korea was given at the 4th International Conference on Behçet's disease (ICBD), preceding academic achievements in following years. After his visit to Kawasaki Medical University and Juntendo University in Japan, Dongsik Bang focused on microstructural studies of Behçet's disease patients and underlying pathophysiology of its cutaneous manifestations. The team demonstrated the pathogenic role of human herpes virus, and established the first successful animal model for the disease ${ }^{10}$. In following years, the team demonstrated the presence of autoantibody in patient sera, which led to the identification of a novel target, $\alpha$-enolase in vascular endothelial cells, for autoimmunity ${ }^{11}$. The steady effort of the research team for over 30 years eventually validated the underlying pathophysiology of the disease. Sungnack Lee published an international textbook through Springer-Verlag entitled "Behçet's disease: a guide to its clinical understanding" with the Korean Study Group of Behçet's disease $^{12}$.

In 2006, Dongsik Bang participated with a group of experts to prepare guidelines for the European League Against Rheumatism (EULAR) guidelines. In 2008, Sungnack Lee and Dongsik Bang were elected as President and Secretary General of the International Society for Behçet's Disease (ISBD), and actively involved themselves as executive committee members to date. Sungnack Lee and Dongsik Bang served as the founding members and laid the cornerstone for the expansion of research in Behçet's Disease.

\section{Photomedicine and vitiligo}

Beginning and development in the fields of photomedicine and vitiligo were achieved by Yoon-Kee Park and SeungKyung Hann. In 1981, Yoon-Kee Park opened the first phototherapy center of Korea in Severance Hospital. In 1984, Yoon-Kee Park designed the first Korean phototherapy apparatus to benefit patients with novel technology. Subsequently, a specialty clinic for vitiligo and psoriasis patients was introduced in 1986. Yoon-Kee Park started photo-chemotherapy protocol using psoralen for psoriasis and vitiligo treatment for the first time in Korea. Yoon-Kee Park and Seung-Kyung Hann published a paper presenting the effective results of autologous epidermal grafting and PUVA in 100 vitiligo patients ${ }^{13}$.

In 1990, the first national symposium for photomedicine was organized to introduce clinical protocols of phototherapy to Korean dermatologists. In 1991 and 1992, International Course on Phototherapy and Phototest was hosted to instruct foreign dermatologists.

The group continued basic research on pigmentary disorders. For the first time in Korea, culture of melanocytes was successfully isolated from the skin of vitiligo patients with self-developed media. In the mid-1990s, they revealed the autoantibodies present in vitiligo patient sera that react with an autoantigen at a molecular weight of 65 $\mathrm{kd}$ in the surface of melanocytes ${ }^{14}$. In recognition to this contribution, Yoon-Kee Park was honored with a Yonsei Academic Award in 1992. Seung-Kyung Hann classified facial segmental vitiligo according to its involved distribution and configuration, and the publication has been highly quoted ${ }^{15-17}$.

\section{Contact dermatitis and atopic dermatitis}

Yonsei Dermatology was the first in Korea to introduce a patch test kit to diagnose allergic contact dermatitis in 1969, when Tae Ha Woo was a department chair ${ }^{18}$. His foresight to the latest diagnostic tool led to the burgeoning of future research in skin immunology.

In 1986, allergy specialty clinic was established in Severance hospital. In 1995, Kwang Hoon Lee initiated developed allergen-specific immunotherapy using house dust mites for atopic dermatitis patients for the first time in Korea. Since its beginning, the specialty clinic for allergen-specific immunotherapy has registered over 800 patients and the successful treatment outcomes were published in $2013^{19}$. Kwang Hoon Lee and his research team have carried out basic and clinical research on abnormalities in atopic dermatitis, connections between stress and immune regulation, and new targets of atopic dermatitis, and his work has been published in high impact journals ${ }^{20-22}$. 
In recognition of his academic and clinical achievement, Kwang Hoon Lee was selected as the Korean representative for the International Eczema Council (IEC), and has been serving as an executive director since 2015. As the paradigm is quickly shifting towards treating immune disorders with biologics, current members are actively involved in global clinical trials of novel biologics under development.

\section{Psoriasis and skin dendritic cells}

A specialty clinic for psoriasis was opened by Yoon-Kee Park in 1986. The research of psoriasis in Yonsei Dermatology was begun by Yoon-Kee Park and Wook Lew. In 2004, Wook Lew visited the laboratory directed by James Krueger in Rockefeller University, who discovered the critical role for interleukin (IL)-23/IL-17 axis in psoriasis. A review article written by Wook Lew on the pathogenesis of psoriasis published during his visit to the Rockefeller University has achieved more than 200 citations to date ${ }^{23}$.

After the 2000s, the immunologic aspect of psoriasis was emphasized as a key pathogenic trigger. Min-Geol Lee is now conducting several international multicenter clinical trials for novel biologics. The research team in psoriasis specialty clinic focuses on identifying the underlying pathomechanisms of psoriasis using human tissues and diverse genetically-engineered mouse models ${ }^{24}$.

Min-Geol Lee started the research of skin dendritic cells in Korea. When he visited $\mathrm{NIH}$ under the supervision of Mark Udey, he demonstrated co-stimulatory molecules and E-cadherin expression in Langerhans cells and epidermal dendritic $\mathrm{T}$ cells ${ }^{25,26}$. Min-Geol Lee continued to decipher the role of dendritic cells in skin disease, and reported numerous basic research publications ${ }^{27}$. Min-Geol Lee served as the vice-president for the 12th International Symposium on Dendritic Cells, elevating the status of dendritic cell research field in Korea.

\section{Skin barrier}

In the 1990s, Seung Hun Lee was the first to introduce the concept of a 'skin barrier' to Korea. He first demonstrated that calcium ion is a crucial signal for permeability barrier recovery when he studied in a laboratory supervised by Peter Elias at University of California, San Francisco ${ }^{28}$. After returning to Korea, he reported that protein kinase $C$ (PKC), especially PKC-delta, mediates extra-intracellular calcium signaling ${ }^{29}$. He also found that electrical or mechanical techniques, such as iontophoresis and sonophoresis, which modulate the epidermal calcium gradient, can trigger the barrier recovery processes, even without barrier perturbation ${ }^{30}$. He also demonstrated that protease activated receptor-2 plays an important role in regulating skin barrier function ${ }^{31}$.

Seung Hun Lee has played a pivotal role in establishing and developing the Korean Society for Skin Barrier Research since 1995. In 2010, the Pan Asian Pacific Skin Barrier Research Society was organized by skin barrier researchers in the Asia-Pacific regions, and Seung Hun Lee was elected as the first president. Human Barrier Research Institute was established in Gangnam Severance Hospital, which has sought to share information on the latest research trends in barrier function of human body. Seung Hun Lee has successfully led the institute organizing academic symposium encompassing fields of human barrier as an integrated system involving skin, gastrointestinal and respiratory system.

\section{Bullous skin disease}

A bullous disease clinic in Gangnam Severance Hospital is the only clinic in Korea now to provide diagnosis, treatment, and research for autoimmune and genetic bullous diseases. Soo-Chan Kim introduced diagnostic methods of immunofluorescences, immunoblotting, and immunoprecipitation. To date, a total of 1,211 patients with autoimmune bullous diseases were registered in this clinic. Soo-Chan Kim firstly reported that envoplakin is an autoantigen of paraneoplastic pemphigus (PNP), and suggested new diagnostic criteria of PNP by analyzing Korean patients $^{32}$. Moreover, the Gangnam Severance bullous specialty clinic was the first to use rituximab in patients with pemphigus in Korea. The group reported the efficacy, therapeutic dosing, and prognosis of rituximab treatment in these patients ${ }^{33}$.

Soo-Chan Kim has also performed indirect immunofluorescence mapping and electron microscopic examination to diagnose epidermolysis bullosa (EB). To date, more than 180 patients with epidermolysis bullosa have been registered with the bullous disease specialty clinic. New cases of epidermolysis bullosa were firstly identified, and the mutations were analyzed in COL7A1 gene in the patients with dystrophic EB and KRT5 and KRT14 gene in the patients with EB simplex in Korea ${ }^{34,35}$. The Korean Epidermolysis Bullosa Society for patient groups was established to support patients and their families in 2003.

\section{Dermatologic surgery and skin cancer}

The dermatologic surgery specialty clinic seeks to cure skin cancers. It was established by Kee Yang Chung when he started Mohs micrographic surgery (MMS) after training with Tatyana Humphreys at Thomas Jefferson University. Since the first case in July of 2000, the total number of patients who had MMS at Yonsei Dermatology has reached 
J Kim, et al

Table 1. Kung Sun Oh memorial lecture and international symposium of cutaneous biology research institute

The 1st 1977. 10. 4 Theodor Nasemann, Goethe University, Germany

"Animal Viruses that Infect Man: Clinical and Laboratory Findings"

The 2nd 1978. 10. 4 Otto Braun-Falco, Munich University, Germany

"Dermatologic Aspects of Hyperlipoproteinemia"

The 3rd 1979. 9. 27 Urs W. Schnyder, Zürich University, Switzerland

"New Findings in Inherited Diseases of the Skin"

The 4th 1980. 10. 2 Harold O. Perry, Mayo Clinic, USA

"Dermatoses that Present with Cutaneous Sclerosis"

The 5th 1981. 9. 25 Atsushi Kukita, Tokyo University, Japan

"Malignant Melanoma in Japan"

The 6th 1982. 9. 21 Enno Christophers, Kiel University, Germany

"Psoriasis- A Complex Disease"

The 7th 1983. 10. 25 Ferdinand Müller, Hamburg University, Germany

"New Developments in the Immunological Understanding and Serodiagnosis of Syphilis"

The 8th 1984. 10. 4 John S. Strauss, University of lowa, USA

"The Management of Acne Based Upon Its Pathologic Mechanism"

The 9th 1985. 10. 4 Klaus Wolff, University of Vienna, Austria

"The Clinical Spectrum of Lupus Erythematosus"

The 10th 1986. 10. 8 A. Bernard Ackerman, New York University, USA

"An Algorithmic method for Histologic Diagnosis of Inflammatory and Neoplastic Skin Diseases by Analysis of Their Patterns"

The 11st 1987. 9. 28 J. Graham Smith, Jr., University of Georgia, USA

"Current Status of the Acquired Immune Deficiency Syndrome"

The 12nd 1988. 10. 4 Stephen I. Katz, National Institutes of Health, USA

"The Skin as an Immunologic Organ"

The 13rd 1989. 9. 28 Ruggero Caputo, University of Milan, Italy

"Histiocytic Syndromes"

The 14th 1990. 9. 27 Irwin M. Freedberg, New York University, USA

"Keratin: from Clones to Clinic"

The 15th 1991. 9. 26 Paul R. Bergstresser, University of Texas, USA

"Mechanisms of Ultraviolet Radiation-Induced Inhibition of Antigen Presentation by Langerhans Cells"

The 16th 1992. 9. 25 Hideoki Ogawa, Juntendo University, Japan

"Effectiveness of PUVA Treatment in Atopic Dermatitis and Barrier Dysfunction"

The 17th 1993. 9. 23 James J. Nordlund, Cincinnati University, USA

"The Pigmentary System- An Expanded Perspective"

The 18th 1994. 9. 28 Karen A. Holbrook, University of Florida, USA

"Understanding Fetal Skin Biology as the Basis for Prenatal Diagnosis of Genetic Skin Disease"

The 19th 1995. 10. 4 Jean-Paul Ortonne, University of Nice, France

"Vitiligo- Current Knowledge-Speculation for the Future"

The 20th 1996. 9. 19 Barbara A. Gilchrest, University of Boston, USA

"Novel Approaches to Photoprotection"

The 21st 1997. 9. 24 Thomas J. Lawley, Emory University, USA

"The Role of Endothelial Cells in the Inflammation and Angiogenesis"

The 22nd 1998. 9. 22 Grant J. Anhalt, Johns Hopkins University, USA

"The Paraneoplastic Pemphigus- Insights into Autoimmunity and Cancer"

The 23rd 1999. 9. 29 Constantin E. Orfanos, Free University of Berlin, Germany

"Dermatology- New Developments and New Challenges"

The 24th 2000. 9. 22 John R. Stanley, University of Pennsylvania, USA

"The Pathophysiology of Pemphigus"

The 25th 2002. 9. 27 Gerd Plewig, Ludwig-Maximilian University of Munich, Germany

"The Many Faces of Rosacea"

The 26th 2003. 9. 25 Jeffrey P. Callen, University of Louisville, USA

"Dermatomyositis- Diagnosis, Evaluation and Management"

The 27th 2004. 9. 15 Mark C. Udey, National Cancer Institute, USA

"Immunotherapy for CTCL- Reasonable Idea or Pipe Dream?"

The 28th 2005. 9. 28 Peter M. Elias, University of California, USA

"Medical Aspects of a Dynamic Stratum Corneum Interface" 
Table 1. Continued

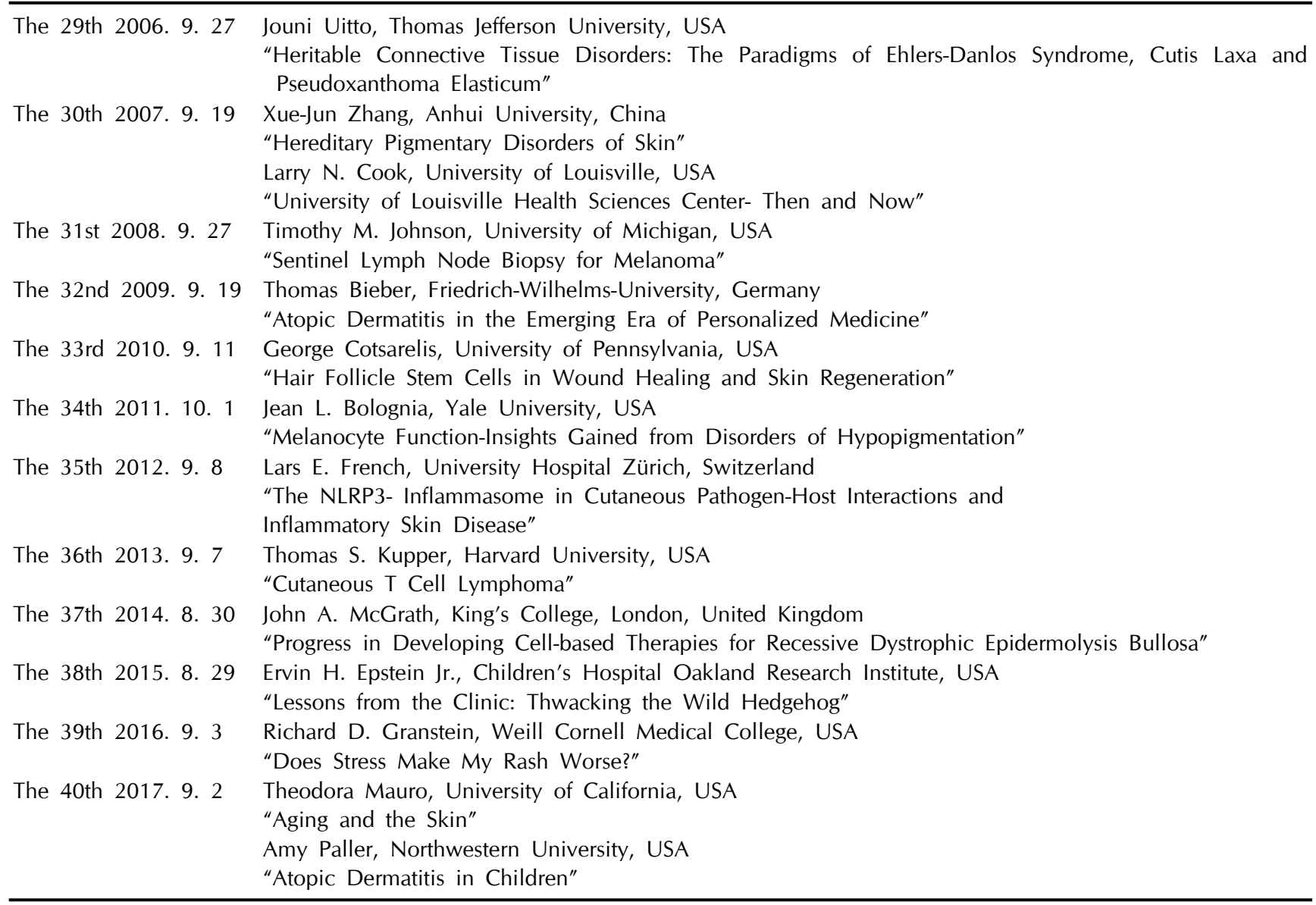

\section{2,300 to date.}

In the 2000s, Min-Geol Lee led the dendritic cell-based immunotherapy for treating advanced stages of melanoma, and performed investigator-initiated clinical trials to evaluate the effect of a dendritic cell vaccine ${ }^{36}$. The clinical and basic research on skin cancers have been avidly pursued under the direction of Kee Yang Chung. Under his guidance, the dermatologic surgery group focus on genetic and clinical features of Korean skin cancer patients, and have proposed innovative surgical techniques ${ }^{37}$. Kee Yang Chung established multidisciplinary management of malignant melanoma, the most lethal form of skin cancer. Furthermore, Yonsei Dermatology also seeks treatments of rare skin cancers, such as dermatofibrosarcoma protuberance, extra-mammary Paget's disease ${ }^{38}$.

In 2012, Yonsei Dermatology organized the first Cutaneous Anatomy Workshop in Severance Hospital, providing a detailed lecture on human facial anatomy and hands-on cadaver dissection. As a selected mentor of the international travelling mentorship program directed by the American Society for Dermatologic Surgery and a board member of the Dermatologic and Aesthetic Surgery
International League, Kee Yang Chung has provided advanced dermatologic surgery training for Korean and foreign-trained dermatologists.

\section{KUNG SUN OH MEMORIAL LECTURE AND INTERNATIONAL SYMPOSIUM OF CUTANEOUS BIOLOGY RESEARCH INSTITUTE}

The Kung Sun Oh Memorial Lecture was initiated in 1977 to commemorate late Professor Kung Sun Oh, the founder of the first dermatology department in Korea. The memorial lecture marked the beginning of international academic exchange in the field of dermatology. It was among the early attempts to introduce Korean dermatology internationally and to absorb advanced dermatological scientific knowledge from the global community. For the memorial lecture, distinguished dermatologists from around the world were invited as guest lecturers ${ }^{39}$. The first invited speaker was Theodor Nasemann from Germany in 1977. Since then, the memorial lecture has been hosted annually. Yonsei Dermatology celebrated its 40th memorial lecture in 2017. All lecturers, who have been invited to 
the Kung Sun Oh Memorial Lecture are listed in Table 1. Since 2003, the International Symposium of Cutaneous Biology Research Institute is hosted on the same day as the Kung Sun Oh Memorial Lecture to broaden the scientific discussion by inviting more distinguished speakers from Korea and overseas. The 15th International Symposium was held in 2017.

Yonsei Dermatology trusts that both events have greatly contributed to the development of modern dermatology and medical science in Korea.

\section{CLOSING REMARKS}

Looking back on our past 100 years, Yonsei Dermatology has achieved great clinical and academic milestones in the history of Korean Dermatology and modern medicine in Korea. Yonsei Dermatology looks forward to future years, daring to lead the next generation of great minds in the field of dermatology and cutaneous biology research.

\section{CONFLICTS OF INTEREST}

The authors have nothing to disclose.

\section{REFERENCES}

1. Yonsei University Medical School Dermatology. Yonsei university medical school dermatology 100 years. Seoul: Koonja; 2017.

2. Roh MR, Lee KH, Lee S. HaeKwan Kung Sun Oh. In: Löser C, Plewig G, Burgdorf W, editors. Pantheon of Dermatology: outstanding historical figures. Heidelberg: Springer, 2013: 816-820.

3. Park YK. Dermatology in Korea. Skinmed 2007;6:107-110.

4. Parish LC, Woo TH. Kung Sun Oh: patriarch of Korean dermatology. Arch Dermatol 1968;98:406-407.

5. Kee CD. Dr. Kung Sun Oh and the department of dermatology of Yonsei university college of medicine. Korean J Med Hist 1996;5:147-154.

6. Bang D, Chung KY. Early roots of western medicine and a pioneer of social work in Korea: Dr. Kung Sun Oh (1878-1963). Yonsei Med J 2016;57:277-282.

7. Lee JB, Lee MG, Kim HI, Lee SN. 19S (IgM) - FTA test in untreated syphilitic patients. Korean J Dermatol 1985;23: 630-634.

8. Lee JB, Farshy CE, Hunter EF, Hambie EA, Wobig GH, Larsen SA. Detection of immunoglobulin $M$ in cerebrospinalfluid from syphilis patients by enzyme-linked-immunosorbent-assay. J Clin Microbiol 1986;24:736-740.

9. Bang DS, Lee ES, Sohn SH, Kim DY, Cho SH, Choi MJ. Behçet's disease in Korea. Seoul: Hanuri, 2013.

10. Sohn S, Lee ES, Bang D, Lee S. Behçet's disease-like symptoms induced by the herpes simplex virus in ICR mice.
Eur J Dermatol 1998;8:21-23.

11. Lee $\mathrm{KH}$, Chung HS, Kim HS, Oh SH, Ha MK, Baik JH, et al. Human alpha-enolase from endothelial cells as a target antigen of anti-endothelial cell antibody in Behçet's disease. Arthritis Rheum 2003;48:2025-2035.

12. Lee $S$, Bang D, Lee ES, Sohn S. Behçet's disease: a guide to its clinical understanding: textbook and atlas. Berlin: Springer, 2001.

13. Hann SK, Im S, Bong HW, Park YK. Treatment of stable vitiligo with autologous epidermal grafting and PUVA. J Am Acad Dermatol 1995;32:943-948.

14. Hann SK, Koo SW, Kim JB, Park YK. Detection of antibodies to human melanoma cells in vitiligo and alopecia areata by western blot analysis. J Dermatol 1996;23:100-103.

15. Hann SK, Lee HJ. Segmental vitiligo: clinical findings in 208 patients. J Am Acad Dermatol 1996;35:671-674.

16. Hann SK, Chang JH, Lee HS, Kim SM. The classification of segmental vitiligo on the face. Yonsei Med J 2000; 41:209-212.

17. Kim DY, Oh SH, Hann SK. Classification of segmental vitiligo on the face: clues for prognosis. Br J Dermatol 2011;164: 1004-1009.

18. Woo TH, Kook HI, Cho KY, Park YK. Clinical observation on the allergic contact dermatities in Korea. Korean J Dermatol 1972;10:77-83.

19. Bae JM, Choi YY, Park CO, Chung KY, Lee KH. Efficacy of allergen-specific immunotherapy for atopic dermatitis: a systematic review and meta-analysis of randomized controlled trials. J Allergy Clin Immunol 2013;132:110-117.

20. Wu WH, Park CO, Oh SH, Kim HJ, Kwon YS, Bae BG, et al. Thymic stromal lymphopoietin-activated invariant natural killer T cells trigger an innate allergic immune response in atopic dermatitis. J Allergy Clin Immunol 2010;126:290299.

21. Noh S, Jin S, Park CO, Lee YS, Lee N, Lee J, et al. Elevated galectin-10 expression of IL-22-producing T cells in patients with atopic dermatitis. J Invest Dermatol 2016;136: 328-331.

22. Jin S, Shin JU, Noh JY, Kim H, Kim JY, Kim SH, et al. DOCK8: regulator of Treg in response to corticotropinreleasing hormone. Allergy 2016;71:811-819.

23. Lew W, Bowcock AM, Krueger JG. Psoriasis vulgaris: cutaneous lymphoid tissue supports T-cell activation and "Type 1" inflammatory gene expression. Trends Immunol 2004;25:295-305.

24. Kim TG, Jee H, Fuentes-Duculan J, Wu WH, Byamba D, Kim DS, et al. Dermal clusters of mature dendritic cells and $\mathrm{T}$ cells are associated with the CCL20/CCR6 chemokine system in chronic psoriasis. J Invest Dermatol 2014; 134:1462-1465.

25. Lee MG, Borkowski TA, Udey MC. Regulation of expression of $\mathrm{B} 7$ by murine Langerhans cells: a direct relationship between B7 mRNA levels and the level of surface expression of B7 by Langerhans cells. J Invest Dermatol 1993; 101:883-886.

26. Lee MG, Tang A, Sharrow SO, Udey MC. Murine dendritic $\mathrm{T}$ cells (DETC) express the homophilic adhesion molecule 
E-cadherin. Epithelial Cell Biol 1994;3:149-155.

27. Park JM, Je JH, Wu WH, Jee $H J$, Lee $S K$, Lee MG. Attenuation of contact hypersensitivity by cell-permeable heat shock protein 70 in BALB/C mouse model. Exp Dermatol 2012;21:969-971.

28. Lee SH, Elias PM, Proksch E, Menon GK, Mao-Quiang M, Feingold KR. Calcium and potassium are important regulators of barrier homeostasis in murine epidermis. J Clin Invest 1992;89:530-538.

29. Ahn BK, Jeong SK, Kim HS, Choi KJ, Seo JT, Choi EH, et al. Rottlerin, a specific inhibitor of protein kinase C-delta, impedes barrier repair response by increasing intracellular free calcium. J Invest Dermatol 2006;126:1348-1355.

30. Lee SH, Choi EH, Feingold KR, Jiang $S$, Ahn SK. lontophoresis itself on hairless mouse skin induces the loss of the epidermal calcium gradient without skin barrier impairment. J Invest Dermatol 1998;111:39-43.

31. Jeong SK, Kim HJ, Youm JK, Ahn SK, Choi EH, Sohn MH, et al. Mite and cockroach allergens activate protease-activated receptor 2 and delay epidermal permeability barrier recovery. J Invest Dermatol 2008;128:1930-1939.

32. Kim SC, Kwon YD, Lee IJ, Chang SN, Lee TG. cDNA cloning of the 210-kDa paraneoplastic pemphigus antigen reveals that envoplakin is a component of the antigen complex. J Invest Dermatol 1997; 109:365-369.

33. Kim TH, Choi Y, Lee SE, Lim JM, Kim SC. Adjuvant rituximab treatment for pemphigus: a retrospective study of 45 patients at a single center with long-term follow up. J Dermatol 2017;44:615-620.

34. Oh SW, Lee JS, Kim MY, Kim SC. COL7A1 mutational analysis in Korean patients with dystrophic epidermolysis bullosa. Br J Dermatol 2007;157:1260-1264.

35. Gu LH, Kim SC, Ichiki Y, Park J, Nagai M, Kitajima Y. A usual frameshift and delayed termination codon mutation in keratin 5 causes a novel type of epidermolysis bullosa simplex with migratory circinate erythema. J Invest Dermatol 2003;121:482-485.

36. Kim DS, Kim DH, Goo B, Cho YH, Park JM, Lee TH, et al. Immunotherapy of malignant melanoma with tumor lysatepulsed autologous monocyte-derived dendritic cells. Yonsei Med J 2011;52:990-998.

37. Oh BH, Jang HS, Lee J, Choi MJ, Nam KA, Chung KY. Delayed reconstruction for the non-amputative treatment of subungual melanoma. Ann Dermatol 2015;27:417-422.

38. Lee KY, Roh MR, Chung WG, Chung KY. Comparison of Mohs micrographic surgery and wide excision for extramammary Paget's disease: Korean experience. Dermatol Surg 2009;35:34-40.

39. Nasemann T. The Kung-Sun-Oh memorial lecture and impressions on dermatology during a trip to South Korea. Hautarzt 1978;29:395-397. 